\title{
Advantages and remaining issues of state-of-the-art $m$-plane freestanding GaN substrates grown by halide vapor phase epitaxy for $m$-plane InGaN epitaxial growth
}

\author{
S F Chichibu ${ }^{1}$, M Kagaya ${ }^{1}$, P Corfdir $^{2}$, J-D Ganière ${ }^{2}$, \\ B Deveaud-Plédran ${ }^{2}$, N Grandjean ${ }^{2}, \mathrm{~S} \mathrm{Kubo}^{3}$ and K Fujito ${ }^{3}$ \\ ${ }^{1}$ CANTech, Institute of Multidisciplinary Research for Advanced Materials, Tohoku University, \\ 2-1-1 Katahira, Aoba, Sendai 980-8577, Japan \\ ${ }^{2}$ Institute of Condensed Matter Physics, Ecole Polytechnique Federale de Lausanne (EPFL), \\ 1015 Lausanne, Switzerland \\ ${ }^{3}$ R\&TD Center, Tsukuba Plant, Optoelectronics Department, Mitsubishi Chemical Corporation, \\ 1000 Higashimamiana, Ushiku 300-1295, Japan \\ E-mail: chichibulab@yahoo.co.jp
}

Received 16 October 2011, in final form 16 November 2011

Published 19 January 2012

Online at stacks.iop.org/SST/27/024008

\begin{abstract}
Advantages and remaining issues of state-of-the-art $m$-plane freestanding GaN (FS-GaN) substrates grown by halide vapor phase epitaxy (HVPE) for $m$-plane $\operatorname{~}_{x} \mathrm{Ga}_{1-x} \mathrm{~N}$ epitaxial film growth by metalorganic vapor phase epitaxy are described. Because of the low threading dislocation and basal-plane stacking fault densities, improved quantum efficiency and short radiative lifetime are achieved for the near-band-edge emission of 200-250 nm thick $m$-plane pseudomorphic $\operatorname{In}_{x} \mathrm{Ga}_{1-x} \mathrm{~N}(x \leqslant 0.14)$ epilayers. Values of full-width at half-maximum for the $\mathrm{X}$-ray $\omega$-rocking curves remain unchanged as the substrate values being 80 and $60 \mathrm{arcsec}$ for the (1010) diffraction with $\langle 0001\rangle$ and $\langle 11 \overline{2} 0\rangle$ azimuths, respectively, and 80 arcsec for the (1012) diffraction. As the surface flatness is greatly improved, the In-incorporation efficiency $\left(\eta_{\text {inc }}^{\text {In }}\right)$ is lower than the cases for conventional $c$-plane growth and $m$-plane growths on defective $\mathrm{GaN}$ bases. The former originates from nonidentical surface kinetics, and the latter is due to the reduction in the area of inclined and tilted planes. Sub-micrometer-wide zonary patterns parallel to the $c$-axis and $2 \mu \mathrm{m}$ long axis figure-of-eight patterns parallel to the $a$-axis are clearly visualized in the monochromatic cathodoluminescence (CL) intensity images. Because the spatio-time-resolved CL measurement reveals very little spatial variation of low-temperature radiative lifetime, the slight peak energy variation is interpreted to originate from nonidentical $\eta_{\text {inc }}^{\text {In }}$ for the growing surfaces exhibiting various miscut angles. The figure-of-eight patterns are ascribed to originate from the anisotropic, severe $m$-plane tilt mosaic along the $a$-axis of the GaN substrate, and the zonary patterns may originate from the $m$-plane tilt mosaic along the $c$-axis. Further reduction in the tilt and twist mosaics is necessary for HVPE of FS-GaN substrates, in order to grow homogeneous InGaN epilayers.
\end{abstract}

(Some figures may appear in colour only in the online journal) 


\section{Introduction}

Wurtzite group-III nitride semiconductors grown in nonpolar and semipolar orientations [1] are a promising candidate for realizing high performance ultimate optoelectronic devices. This is because the quantum wells (QWs) fabricated on offpolar planes suffer from less-pronounced unwanted quantumconfined Stark effects which are caused by the immobile interfacial charges induced by the polarization discontinuity along the $c$-axis and reduce the oscillator strength of electronhole pairs in $c$-plane QWs [2-6]. The output power of nonpolar $\mathrm{In}_{x} \mathrm{Ga}_{1-x} \mathrm{~N}$ QW light-emitting diodes (LEDs) fabricated on heteroepitaxial substrates, however, has been lower $[7,8]$ than the conventional $c$-plane LEDs due to the presence of high density threading dislocations (TDs) and basal-plane stacking faults (BSFs) $[9,10]$.

A variety of lateral epitaxial overgrowth (LEO) techniques have been used to reduce the TD density $[9,10]$. However, one of the drawbacks of nonpolar and semipolar growths is that BSFs seldom vanish and rather propagate throughout the epilayer once they are formed, even in thick films or windows and N-polar wings of LEO GaN $[9,10]$. Such TDs and BSFs roughen the surface morphology and give rise to macroscopic compositional inhomogeneity in InGaN alloy films [11-14], because In-incorporation efficiency $\left(\eta_{\text {inc }}^{\text {In }}\right)$ differs depending on the crystallographic orientation of the growth front [15].

Recently, InGaN/GaN high brightness LEDs [16] and laser diodes [17-20] have been demonstrated using low TD and BSF density $m$-plane [16-18] and (202̄1)-plane [19, 20] freestanding $\mathrm{GaN}$ (FS-GaN) substrates grown by halide vapor phase epitaxy (HVPE) [21]. However, because the state-ofthe-art off-polar FS-GaN substrates are usually sliced from a certainly bowed, more than $1 \mathrm{~cm}$ thick, $c$-plane FS-GaN boule grown on (0001) $\mathrm{Al}_{2} \mathrm{O}_{3}$ substrates, the tilt and twist mosaics of the initial $c$-plane FS-GaN are transferred to in-plane twist plus tilt mosaics all around the $c$-axis and anisotropic greater $m$-plane tilt mosaic along the $a$-axis, respectively, as shown in figure 1(a). Accordingly, x-ray $\omega$-rocking curves of the FS-GaN substrate exhibit multiple-peaked or asymmetric lineshapes, as shown in figure 1(b). Such a multiple-domain structure is carried over to the GaN homoepitaxial films [22]. These residual mosaics are the origin of unintentional miscut of the substrate surface, which gives rise to the evolution of inclined planes, resulting in undulated surface morphology of GaN [23]. Accordingly, there remain concerns if such structural imperfections would cause inhomogeneous incorporation of In during the InGaN growths [11-15]. As a matter of fact, the full-width at half-maximum (FWHM) values for the near-band-edge (NBE) photoluminescence (PL) peak of the $m$-plane $\mathrm{In}_{x} \mathrm{Ga}_{1-x} \mathrm{~N}$ epilayers $[8,16,24]$ grown by metalorganic vapor phase epitaxy (MOVPE) on FS-GaN were larger than those for $c$-plane $\mathrm{In}_{x} \mathrm{Ga}_{1-x} \mathrm{~N}$ epilayers [25] of the same $\mathrm{InN}$ mole fractions $(x)$.

In this paper, first we demonstrate the improved structural and optical qualities of $m$-plane $\operatorname{In}_{x} \mathrm{Ga}_{1-x} \mathrm{~N}$ films grown on the low TD and BSF density $m$-plane FS-GaN substrates [21]. Reasonably high equivalent internal quantum efficiency $\left(\eta_{\text {int }}^{\text {eq }}\right)$, which is approximated as the spectrally integrated weakly

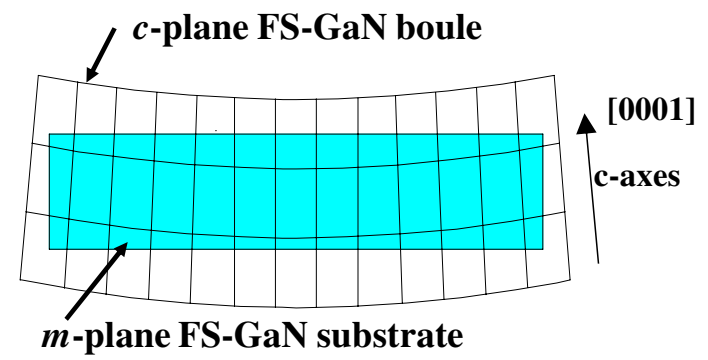

(a)

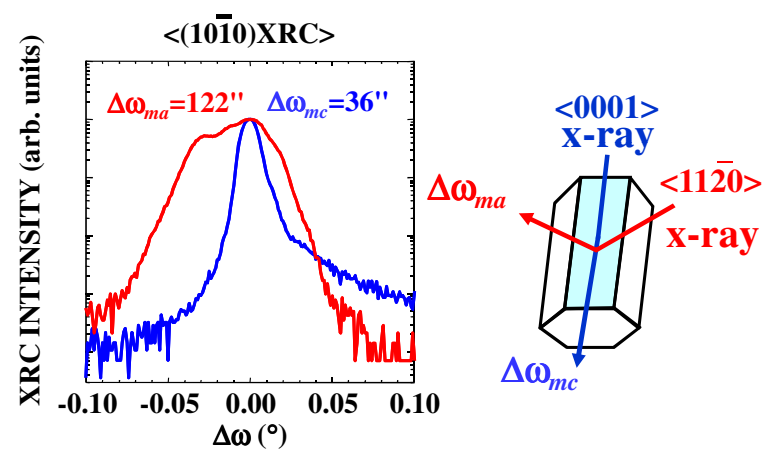

(b)

Figure 1. (a) Schematic cross-sectional representation of a $c$-plane FS-GaN boule detached from a sapphire substrate grown by HVPE. The shaded rectangle represents an $m$-plane FS-GaN substrate. $(b)$ $\mathrm{XRCs}$ for the (1010) diffraction of the $m$-plane FS-GaN substrate. $\Delta \omega_{m c}$ and $\Delta \omega_{m a}$ represent the FWHM values for the (1010) XRCs taken along the $c$-axis and $a$-axis, respectively.

excited $\left(\sim 38 \mathrm{~W} \mathrm{~cm}^{-2}\right)$ PL intensity at $T \mathrm{~K}$ divided by that at $8 \mathrm{~K}\left[I_{\mathrm{PL}}(T \mathrm{~K}) / I_{\mathrm{PL}}(8 \mathrm{~K})\right]$, and short radiative lifetime for the NBE emission are demonstrated. Simultaneously, the issues in growing atomically flat films of high $x$ values are pointed out, according to the fact that the pure $m$-plane exhibits quite low $\eta_{\text {inc }}^{\text {In }}$ [24]. Then, we focus on the results of spatio-timeresolved cathodoluminescence (STRCL) measurements on the $m$-plane $\operatorname{In}_{0.05} \mathrm{Ga}_{0.95} \mathrm{~N}$ epilayer [26]. Local variation in the cathodoluminescence (CL) peak energy is attributed to a slight difference in the local $x$ value caused by the residual structural imperfections. The bowing and tilt/twist mosaics of FS-GaN are shown to generate non-negligible overlayer structural imperfections, namely inclined and heavily tilted surface planes.

\section{Experimental details}

Approximately 200 to $250 \mathrm{~nm}$ thick $m$-plane $\mathrm{In}_{x} \mathrm{Ga}_{1-x} \mathrm{~N}$ films $(x \leqslant 0.14)$ were grown using an MOVPE apparatus $[22,24]$ on $\sim 8 \times 15 \mathrm{~mm}^{2}$ area, $325 \mu \mathrm{m}$ thick $m$-plane FSGaN substrates grown by HVPE (Mitsubishi Chemical Co.) $[21,22]$. The TD and BSF densities were lower than $5 \times 10^{6}$ and $1 \times 10^{3} \mathrm{~cm}^{-1}$, respectively [21]. For comparison, $c$-plane FS-GaN [27] and $\mathrm{GaN}$ on $\mathrm{Al}_{2} \mathrm{O}_{3}$ epitaxial templates were also used. Their TD densities were lower than $10^{7} \mathrm{~cm}^{-2}$ and approximately $10^{9} \mathrm{~cm}^{-2}$, respectively. Prior to the $\mathrm{InGaN}$ growth, a $1.5 \mu \mathrm{m}$ thick $\mathrm{GaN}$ was homoepitaxially grown using trimethylgallium (TMGa) and ammonia $\left(\mathrm{NH}_{3}\right)$. The growth temperature $\left(T_{g}\right)$, mole flow ratio of $\mathrm{NH}_{3}$ to $\mathrm{TMGa}$ (V/III ratio), 
reactor pressure, growth rate and carrier gas were $1090{ }^{\circ} \mathrm{C}$, $5000,5.3 \times 10^{4} \mathrm{~Pa}, 1.5 \mu \mathrm{m} \mathrm{h}^{-1}$ and $\mathrm{Pd}$-purified $\mathrm{H}_{2}$, respectively [22]. Trimethylindium was used for the InGaN film growth $\left(750^{\circ} \mathrm{C} \leqslant T_{g} \leqslant 820^{\circ} \mathrm{C}, 40000 \leqslant \mathrm{~V} / \mathrm{III} \leqslant 1000000,6.6 \times\right.$ $10^{4} \mathrm{~Pa}, 0.1 \mu \mathrm{m} \mathrm{h}^{-1}$ and $\mathrm{N}_{2}$, respectively).

Steady-state PL was excited using the $325.0 \mathrm{~nm}$ line of a $\mathrm{cw} \mathrm{He}-\mathrm{Cd}$ laser $\left(38 \mathrm{~W} \mathrm{~cm}^{-2}\right)$. Time-resolved photoluminescence (TRPL) was excited using the frequencydoubled mode-locked $\mathrm{Al}_{2} \mathrm{O}_{3}$ :Ti laser. The wavelength, pulse duration and the power density were $361 \mathrm{~nm}, \sim 100 \mathrm{fs}$ and $120 \mathrm{~nJ} \mathrm{~cm}{ }^{-2}$ per pulse, respectively.

STRCL measurement [26] was carried out exclusively on the $m$-plane $\mathrm{In}_{0.05} \mathrm{Ga}_{0.95} \mathrm{~N}$ epilayer using a picosecond pulsed electron gun equipped with a scanning electron microscope (SEM) [28, 29]. As well as the scanning near-field optical microscopy, this technique is quite attractive in understanding the diffusion and recombination processes of carriers and excitons in complex nanostructures, because of its high spatial and temporal resolutions. The pulsed electron beam (e-beam) was generated by irradiating the femtosecond pulses of a frequency-tripled mode-locked $\mathrm{Al}_{2} \mathrm{O}_{3}$ :Ti laser on the $\mathrm{Au}$ photocathode [28]. The wavelength, pulse duration and repetition rate were $266 \mathrm{~nm}, 200 \mathrm{fs}$ and $80.7 \mathrm{MHz}$, respectively. The acceleration voltage and probe current at the sample surface were $8 \mathrm{kV}$ and $10 \mathrm{pA}$, respectively. The luminescence was dispersed by a grating monochromator and detected using a streak camera. The temporal resolution was approximately 10 ps. All the CL measurements were carried out at $32 \mathrm{~K}$.

\section{Results and discussion}

\subsection{Structural properties of $\operatorname{In}_{x} G a_{1-x} N$ epilayers $(x \leqslant 0.14)$}

According to the reduction of extended defects in the FSGaN substrate, present $m$-plane $\operatorname{In}_{x} \mathrm{Ga}_{1-x} \mathrm{~N}$ films do not exhibit large-scale distinct striated, tilted or inclined surface morphology that was observed in InGaN QWs [14] and LEDs [13] grown on the defective $m$-plane FS-GaN substrate $[9,10]$. Also, as expected from the crystallographic orientation, so-called $V$-defects often observed in $c$-plane InGaN films [30] are absent. As a result, the root-mean-square roughness value obtained from the atomic-force microscopy (AFM) observation is typically less than $0.39 \mathrm{~nm}$ for $1 \mu \mathrm{m} \times 1 \mu \mathrm{m}$ area and $0.72 \mathrm{~nm}$ for $5 \mu \mathrm{m} \times 5 \mu \mathrm{m}$ area. These are more than one and a half orders of magnitude smaller than the defective $m$-plane InGaN structures $[13,14]$. As shown in the planview and cross-sectional transmission electron microscopy (TEM) images in figures $2(a)$ and $(b)$, respectively, distinct TDs or BSFs are not found in the $\mathrm{In}_{0.05} \mathrm{Ga}_{0.95}$ N/GaN/FS-GaN structure entirely.

According to the appearance of atomically flat surface morphology, messy In-incorporation inhomogeneity seen in defective $m$ - and $a$-plane InGaN QWs [11-14] was eliminated. However, average $\eta_{\text {inc }}^{\text {In }}$ was lower than $c$-plane growths on FS-GaN and $\mathrm{GaN} / \mathrm{Al}_{2} \mathrm{O}_{3}$, as shown in figure 3. Such a difference in $\eta_{\text {inc }}^{\text {In }}$ may arise from nonidentical surface kinetics among the different planes $[31,32]$. Also, $\eta_{\text {inc }}^{\text {In }}$ of the present $m$-plane growth is lower than the growths on defective

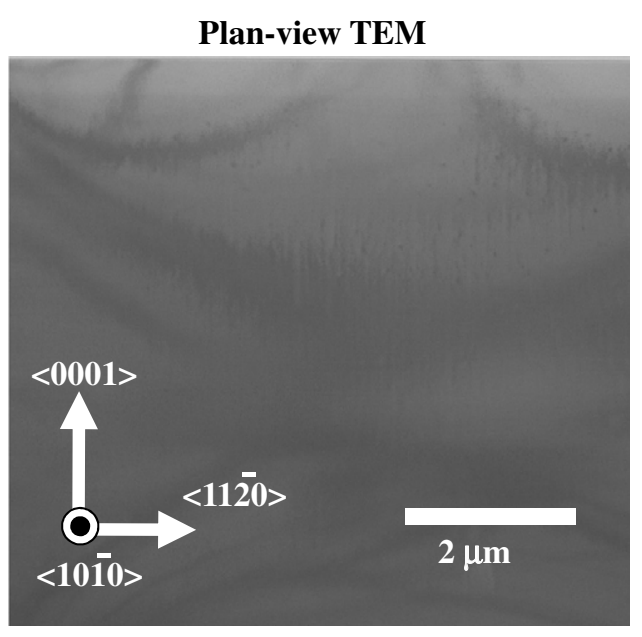

(a)

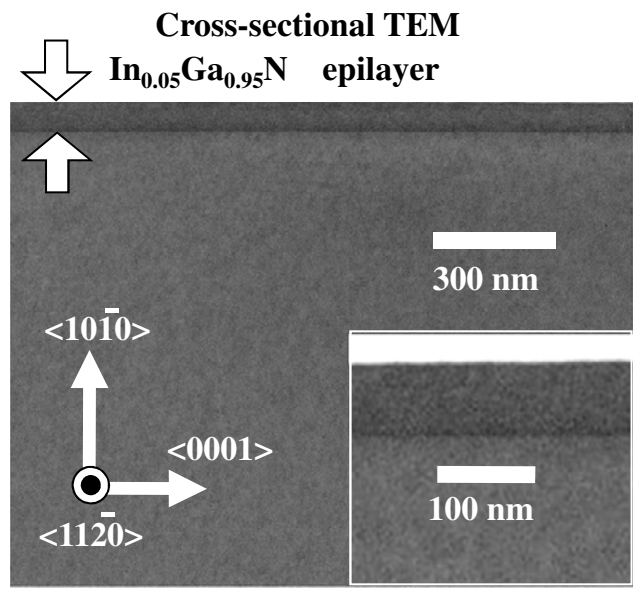

(b)

Figure 2. (a) Plan-view and (b) cross-sectional TEM images for a $70 \mathrm{~nm}$ thick $m$-plane $\mathrm{In}_{0.05} \mathrm{Ga}_{0.95} \mathrm{~N}$ epilayer grown on the $m$-plane FS-GaN. The $e$-beam incidence for (b) was parallel to the $\langle 11 \overline{2} 0\rangle$ axis.

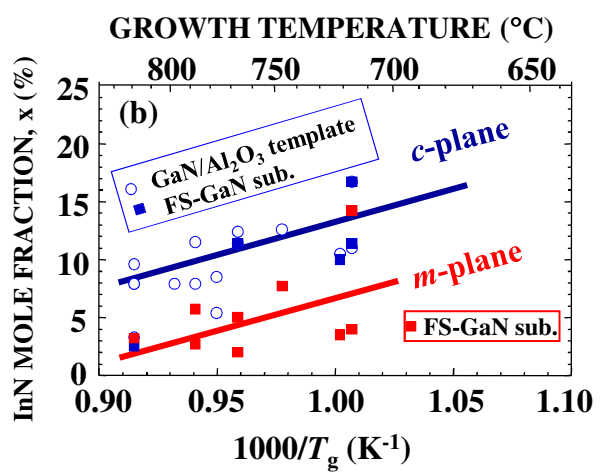

Figure 3. InN mole fraction $x$ for the $\operatorname{In}_{x} \mathrm{Ga}_{1-x} \mathrm{~N}$ epilayers grown simultaneously on the $m$ - and $c$-plane FS-GaN and $\mathrm{GaN} / \mathrm{Al}_{2} \mathrm{O}_{3}$ as a function of $T_{g}$.

nonpolar substrates [11-14] due to the reduced total area of inclined/tilted planes [14].

All the $\operatorname{In}_{x} \mathrm{Ga}_{1-x} \mathrm{~N}$ films $(x \leqslant 0.14)$ are confirmed by $\mathrm{x}$-ray reciprocal space mapping (X-RSM) measurements to grow coherently on the base $\mathrm{GaN}$, as shown in figures 4(a) and (b) for example $(x=0.08)$. The $x$ values are then calculated for 

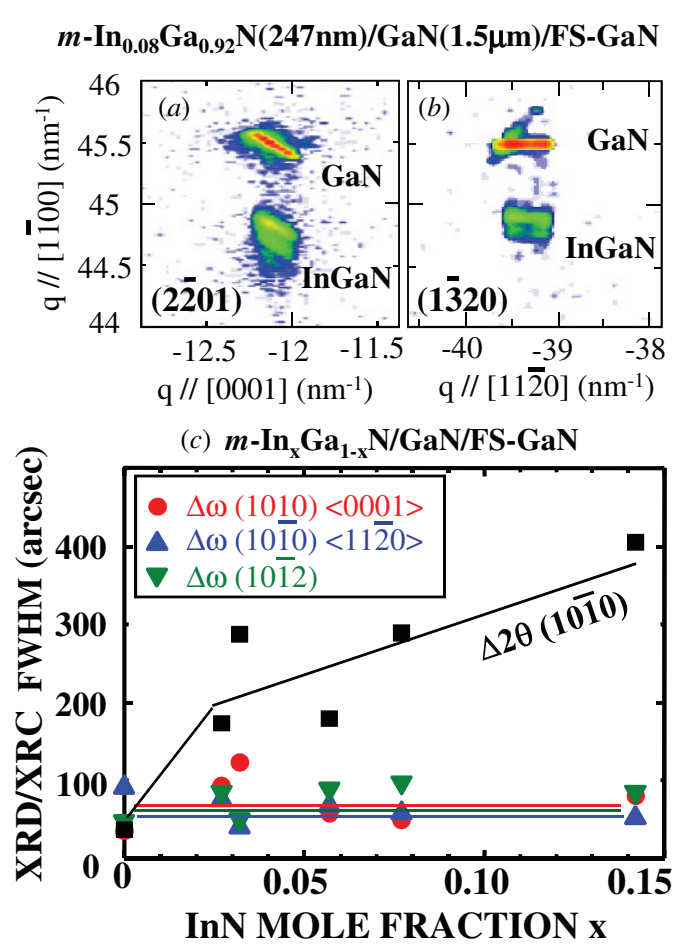

Figure 4. X-RSM images for the $247 \mathrm{~nm}$ thick $m$-plane $\mathrm{In}_{0.08} \mathrm{Ga}_{0.92} \mathrm{~N}$

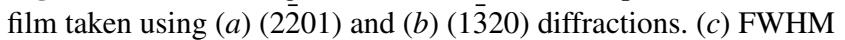
values obtained for the $2 \theta-\omega$ scan $(\Delta 2 \theta)$ of $(10 \overline{1} 0)$ diffraction and $\omega$-scans $(\Delta \omega)$ of (1010) and (1012) diffractions of approximately $250 \mathrm{~nm}$ thick $m$-plane $\operatorname{In}_{x} \mathrm{Ga}_{1-x} \mathrm{~N}$ films as a function of $x$.

the films suffering from triaxial anisotropic stress $\left(C_{2 v}\right)$ [14], where elastic stiffness constants of the alloys are assumed to obey Vegard's law. The FWHM value for the (1010) $2 \theta-\omega$ scans $(\Delta 2 \theta)$ increases with increasing $x$, as shown in figure $4(c)$, indicating the increase in a plane-distance fluctuation due to the compositional (or strain) inhomogeneity. However, the FWHM values for the $\omega$-rocking curves $(\Delta \omega)$ are nearly unchanged from the substrate values, as shown in figure $4(c)$ : approximately 80 and $60 \operatorname{arcsec}$ for (1010) diffraction along $\langle 0001\rangle\left(\Delta \omega_{m c}\right)$ and $\langle 11 \overline{2} 0\rangle$ azimuths $\left(\Delta \omega_{m a}\right)$, respectively, and $80 \operatorname{arcsec}$ for $(10 \overline{1} 2)$ diffraction $\left(\Delta \omega_{r}\right)$. The results indicate that TD densities responsible for the tilt and twist mosaics of the $\operatorname{In}_{x} \mathrm{Ga}_{1-x} \mathrm{~N}$ films are comparable to those of the substrate. These results are consistent with the fact that the $m$-plane FS-GaN substrate exhibits a larger $\Delta \omega_{m a}$ value $[21,22]$.

\subsection{Optical properties of $\operatorname{In}_{x} G a_{1-x} N$ epilayers $(x \leqslant 0.14)$}

All the $\operatorname{In}_{x} \mathrm{Ga}_{1-x} \mathrm{~N}$ films $(x \leqslant 0.14)$ exhibit a predominant NBE emission peak at $293 \mathrm{~K}$, as shown in figure 5. Its FWHM value essentially increases with $x$, being consistent with the increase in $\Delta 2 \theta$ of the (10 $\overline{10}$ ) peak. However, the value of $\eta_{\text {int }}^{\text {eq }}$ at $300 \mathrm{~K}$ increases from approximately $5 \%$ for $x=0.02$ to $11 \%$ for $x=0.06$, as is the case with defective $c$ - and $a$-plane InGaN films [6]. Although the highest value is yet $11 \%$, the $\eta_{\text {int }}^{\text {eq }}$ values of the present epilayers are higher than those of the defective $a$-plane $\operatorname{In}_{x} \mathrm{Ga}_{1-x} \mathrm{~N}$ films [6] for the same $x$. We note that $\eta_{\text {int }}^{\text {eq }}$ naturally increases by employing QW structures: $\eta_{\text {int }}^{\text {eq }}$ for the

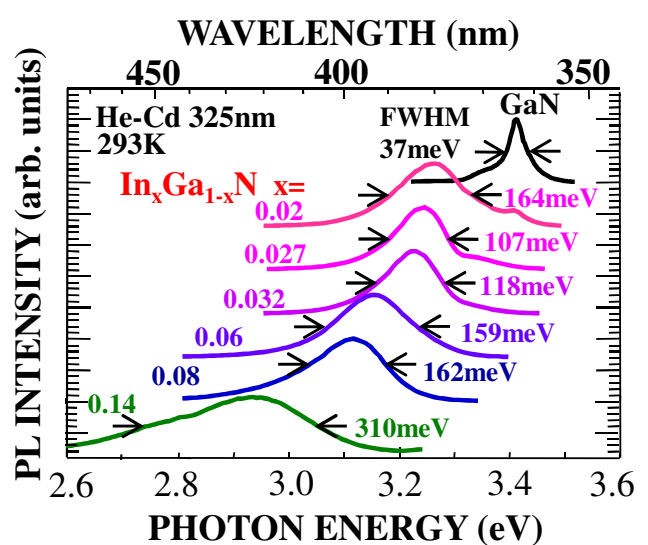

Figure 5. Room temperature PL spectra of approximately $250 \mathrm{~nm}$ thick $m$-plane $\operatorname{In}_{x} \mathrm{Ga}_{1-x} \mathrm{~N}$ epilayers as a function of $x$.
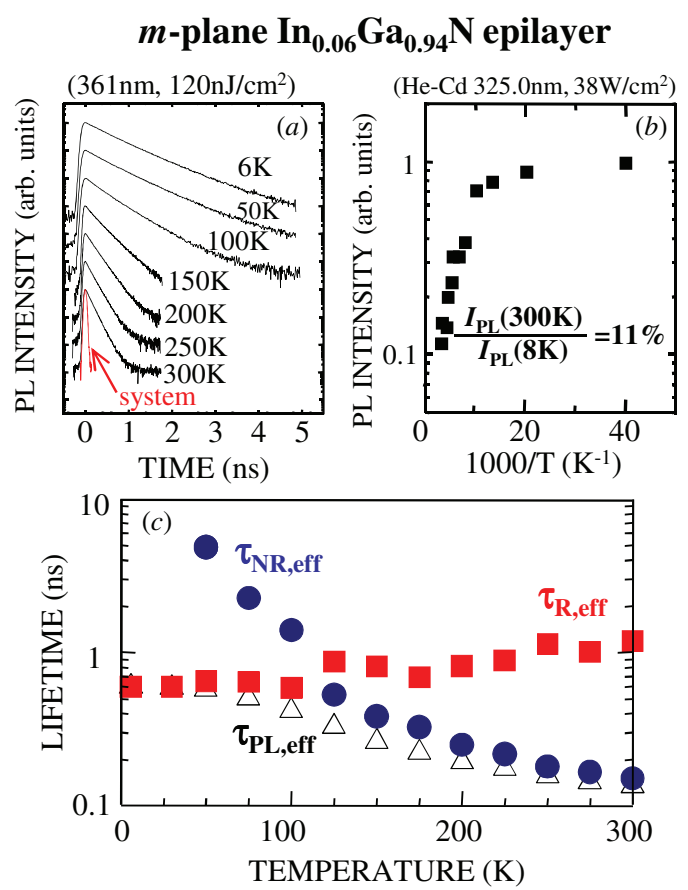

Figure 6. (a) TRPL singals, $(b) \eta_{\mathrm{int}}^{\mathrm{eq}}\left[I_{\mathrm{PL}}(T \mathrm{~K}) / I_{\mathrm{PL}}(8 \mathrm{~K})\right]$ and $(c)$ $\tau_{\mathrm{PL} \text {,eff }}, \tau_{\mathrm{NR} \text {,eff }}$ and $\tau_{\mathrm{R} \text {,eff }}$ of the $m$-plane $\mathrm{In}_{0.06} \mathrm{Ga}_{0.94} \mathrm{~N}$ epilayer grown on FS-GaN as a function of temperature.

$426 \mathrm{~nm}$ emission of the $m$-plane $\mathrm{In}_{0.11} \mathrm{Ga}_{0.89} \mathrm{~N} / \mathrm{GaN}$ QW LD wafer was $44 \%$ [33].

TRPL signals of the NBE peak for the $m$-plane $\mathrm{In}_{0.06} \mathrm{Ga}_{0.94} \mathrm{~N}$ epilayer are shown as a function of temperature in figure 6(a). As the decay curves exhibit nonideal single-exponential line shapes, the effective PL lifetime $\left(\tau_{\mathrm{PL}, \text { eff }}\right)$ is defined as the time after excitation when $\int_{0}^{\tau_{\mathrm{PL}, \text { eff }}} I(t) \mathrm{d} t / \int_{0}^{t_{\mathrm{lim}}} I(t) \mathrm{d} t$ becomes $1-1 / e$, where $I(t)$ is the intensity at time $t$ and $t_{\text {lim }}$ is the time when $I\left(t_{\text {lim }}\right)$ becomes $0.01 I(0)$. From the values of $\eta_{\text {int }}^{\text {eq }}$ and $\tau_{\mathrm{PL}, \text { eff }}$ shown in figures $6(b)$ and $(c)$, respectively, the effective radiative lifetime $\left(\tau_{\mathrm{R}, \text { eff }}\right)$ and effective nonradiative lifetime $\left(\tau_{\mathrm{NR}, \mathrm{eff}}\right)$ at each temperature are calculated using the relations $\eta_{\text {int }}^{\text {eq }}=(1+$ $\left.\tau_{\mathrm{R}, \text { eff }} / \tau_{\mathrm{NR}, \text { eff }}\right)^{-1}$ and $\tau_{P L \text {,eff }}^{-1}=\tau_{R \text {,eff }}^{-1}+\tau_{N R \text {,eff }}^{-1}$, and the results are shown in figure $6(c)$. As shown, $\tau_{\mathrm{R} \text {,eff }}$ at $8 \mathrm{~K}(600 \mathrm{ps})$ is longer than that of free A-exciton recombination in $\mathrm{GaN}$ 


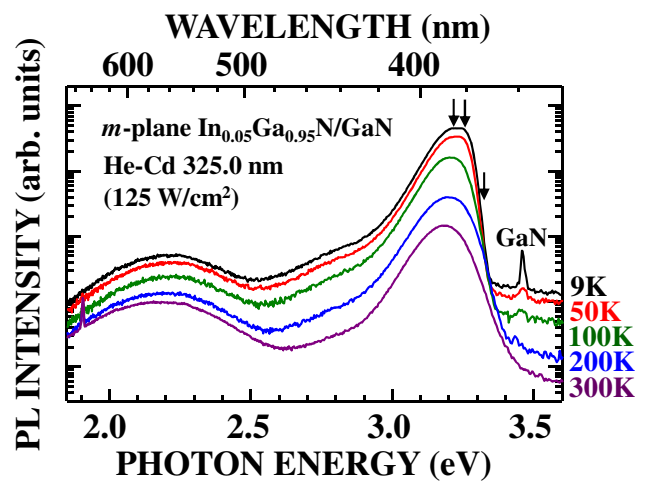

Figure 7. Macroscopic PL spectra for the $70 \mu \mathrm{m}$ thick $m$-plane $\mathrm{In}_{0.05} \mathrm{Ga}_{0.95} \mathrm{~N}$ epilayer as a function of temperature. Three vertical arrows indicate the energies at which the spatially resolved CL intensity images in figures $8(b),(c)$ and $(d)$ were taken.

(125 ps) [34]. Both the long $\tau_{\mathrm{R}, \text { eff }}$ and the fact that $\tau_{\mathrm{R}, \text { eff }}$ does not increase markedly up to $100 \mathrm{~K}$ imply that the emission has a bound or localized exciton character $[3,6]$. Nevertheless, the low temperature $\tau_{\mathrm{R} \text {,eff }}(600 \mathrm{ps})$ is much shorter than $c$ plane GaN/AlGaN or InGaN/GaN QWs ( a few ns) $[35,36]$. Also, $\tau_{\mathrm{R}, \text { eff }}$ at $300 \mathrm{~K}(\sim 1.2 \mathrm{~ns})$ is shorter than those of defective $a$ - and $c$-plane InGaN films [6], indicating fewer influences due to extended defects. Because $\tau_{\mathrm{NR} \text {, eff }}$ at $300 \mathrm{~K}$ is yet as short as $150 \mathrm{ps}$, further reduction in the density of nonradiative point defects $[6,37]$ is mandatory.

\subsection{Impacts of crystal mosaics on the local emission inhomogeneity}

The macroscopic PL spectrum of the $m$-plane $\operatorname{In}_{0.05} \mathrm{Ga}_{0.95} \mathrm{~N}$ epilayer measured at $9 \mathrm{~K}$ exhibits a predominant NBE emission peak at $3.21 \mathrm{eV}$, as shown in the topmost trace in figure 7 . The excitation power density for this particular measurement was $125 \mathrm{~W} \mathrm{~cm}^{-2}$ [26]. It also exhibits a sharp peak at $3.458 \mathrm{eV}$ and spectrally broad luminescence bands at around 2.8 and $2.2 \mathrm{eV}$. The latter three emissions are assigned, respectively, as being due to an unabsorbed bound excitonic emission, socalled blue luminescence band and yellow luminescence band originating from the $\mathrm{GaN}$ underlayer. The peak energy for the NBE emission of $\mathrm{In}_{0.05} \mathrm{Ga}_{0.95} \mathrm{~N}$ first shifts to the lower energy by $21 \mathrm{meV}$ between 40 and $150 \mathrm{~K}$, followed by a blueshift and the second moderate redshift with temperature rise (data not shown). The gross shift being $34 \mathrm{meV}$ is approximately a half of the bandgap energy change of $\mathrm{GaN}$ between 10 and $300 \mathrm{~K}$ ( $\sim 65 \mathrm{meV}$ ) [38]. The result implies the presence of certain bound-type band-tail states. The FWHM value for the NBE peak increases from $143 \mathrm{meV}$ at $9 \mathrm{~K}$ to $170 \mathrm{meV}$ at $180 \mathrm{~K}$, indicating the thermal redistribution of excitons. Apparently, the FWHM values are larger than those for conventional $c$-plane $\mathrm{In}_{0.05} \mathrm{Ga}_{0.95} \mathrm{~N}$ film [25], indicating that $m$-plane InGaN tends to have severer compositional inhomogeneity.

Although the majority of the wafers exhibit flat surface morphology with monolayer or bilayer atomic step lines, approximately $5 \mu \mathrm{m}$ long inclined planes forming the striations along the $a$-axis (parallel to the $c$-plane) are often observed, as shown in the bird's-eye-view AFM image in

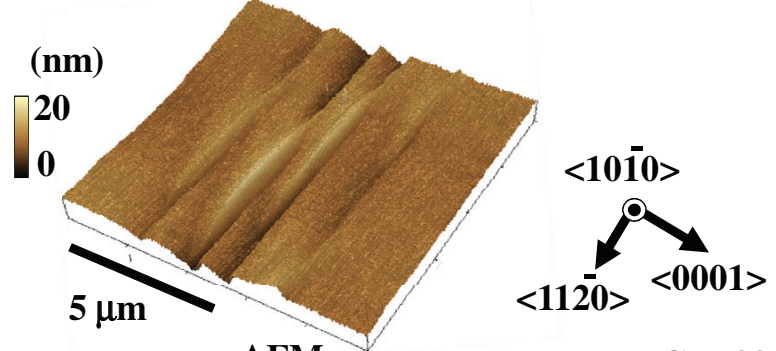

(a) AFM

CL: 32 K
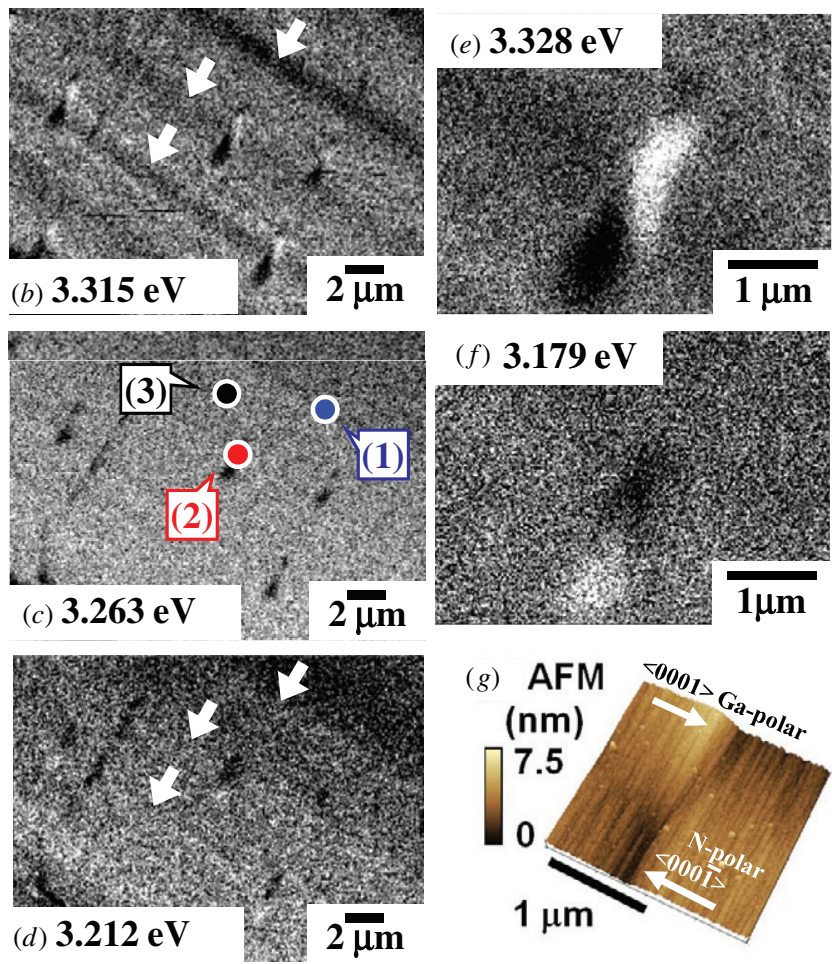

Figure 8. (a) The AFM image of the $m$-plane $\operatorname{In}_{0.05} \mathrm{Ga}_{0.95} \mathrm{~N}$ epilayer grown on the defective N-polar edge area of the wafer. Spatially resolved monochromatic CL intensity images taken at $(b) 3.315$, (c) 3.263 and $(d) 3.212 \mathrm{eV}$. Magnified CL intensity images taken around the figure-of-eight pattern at $(e) 3.328$ and $(f) 3.179 \mathrm{eV}$. $(g)$ Magnified AFM image for the area in the vicinity of the figure-of-eight pattern. All of the CL images were taken at $32 \mathrm{~K}$ with the $8 \mathrm{kV}$ acceleration voltage. The markers (1)-(3) in (c) represent the positions where the STRCL signals shown in figure $9(b)$ were measured.

figure $8(a)$. Steady-state monochromatic CL intensity images taken at $3.315,3.263$ and $3.212 \mathrm{eV}$ in the area close to figure $8(a)$ are shown in figures $8(b),(c)$ and $(d)$, respectively. The monitored photon energies are shown by the arrows in figure 7. The image taken at $3.315 \mathrm{eV}$ (figure $8(b)$ exhibits striated dark zones (belts) almost parallel to the $c$-axis as shown by white arrows. However, the zonary pattern loses the contrast when the monitoring photon energy is lower than $3.263 \mathrm{eV}$, as shown in figures $8(c)$ and $(d)$ (see white arrows in $(d)$ ). Another distinct feature in figures $8(b)-(d)$ is the presence of approximately $2 \mu \mathrm{m}$ long axis figure-of-eight patterns aligned parallel to the $a$-axis. The bright area within the figure-of-eight patterns is completely reversed in the monochromatic CL images taken at 3.328 and $3.179 \mathrm{eV}$, as shown in figures $8(e)$ and $(f)$, respectively. Here 

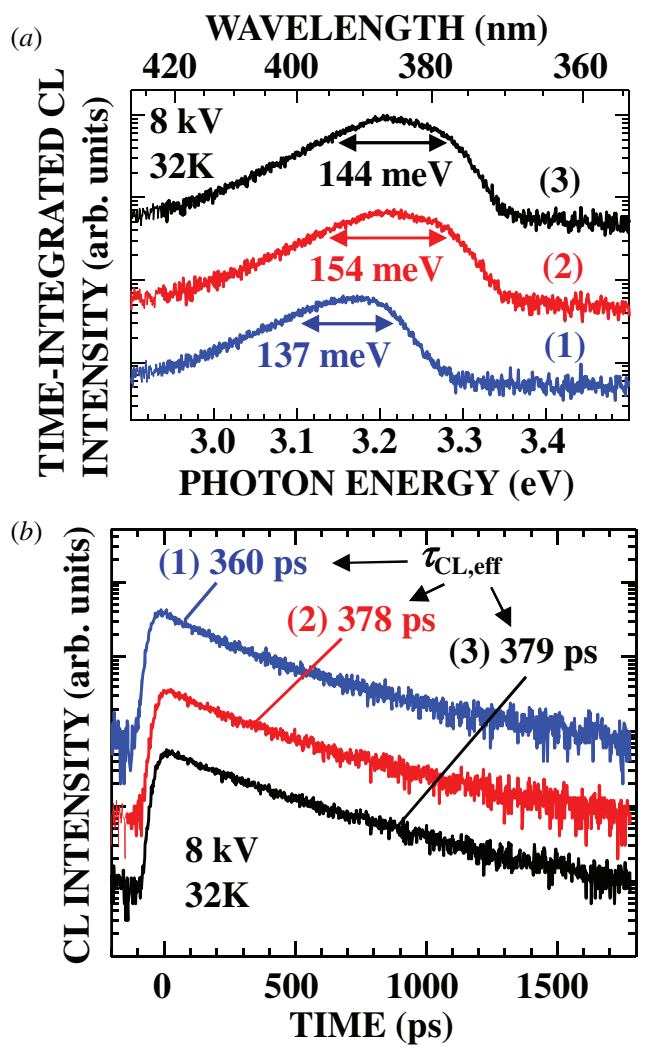

Figure 9. (a) Spot-excitation time-integrated CL spectra taken at positions (1)-(3) in figure 8(c). (b) STRCL signals measured at the positions (1)-(3) in figure $8(c)$ at $32 \mathrm{~K}$. The $\tau_{\mathrm{CL}, \text { eff }}$ values are also shown.

we mention that the SEM image taken at the corresponding area is seen as featureless.

In order to explore the origin of the spatial and spectroscopic emission inhomogeneity shown above, STRCL spectroscopy was implemented. The time-integrated spotexcitation local CL spectra measured at $32 \mathrm{~K}$ for the positions marked by (1)-(3) in figure $8(c)$ are shown in figure $9(a)$. The monitored positions are within the (1) striated, dark CLimage zone at $3.315 \mathrm{eV}$, (2) higher CL peak energy area in the figure-of-eight pattern and (3) featureless CL-image area. The peak energy and FWHM value for the CL peak in spot (1) are $3.17 \mathrm{eV}$ and $137 \mathrm{meV}$, respectively. Because the NBE CL spectra for spots (2) and (3) contain higher energy emission components, their FWHM values are larger than that for (1). The result means that the bandgap inhomogeneity is severer in portions (2) and (3): i.e. they contain the areas of low $\mathrm{InN}$ mole fraction. Much severer compositional inhomogeneity has been found [11-14] in nonpolar $\operatorname{In}_{x} \mathrm{Ga}_{1-x} \mathrm{~N}$ films grown on heteroepitaxial or defective substrates. In those cases, the primary reason for the inhomogeneity is the presence of high density TDs and BSFs: they generate various inclined planes and facets having different surface bond configurations: i.e. different $\eta_{\text {inc }}^{\text {In }}$. Because the present $m$-plane $\operatorname{In}_{0.05} \mathrm{Ga}_{0.95} \mathrm{~N}$ film does not contain distinct TDs or BSFs, as shown in figure 2, the spectral inhomogeneity observed in figure $9(a)$ is probably due to slight but non-negligible variation in $\eta_{\text {inc }}^{\text {In }}$ in spots (1)-(3).

To verify this simple consideration, spectrally integrated STRCL signals measured at the corresponding spots are shown in figure $9(b)$. As all the signals do not exhibit an ideal exponential decay shape, the effective CL lifetime $\left(\tau_{\mathrm{CL}, \text { eff }}\right)$ is defined [6] using similar relations used for the PL case. The $\tau_{\mathrm{CL} \text {,eff }}$ values are nearly constant irrespective of the position or photon energy: 360 ps for (1), 378 ps for (2) and 379 ps for (3). Here we note that the local CL spectra and local time-resolved cathodoluminescence (TRCL) signal for the lower CL peak energy area within the figure-of-eight patterns are similar to those for spot (1). The result indicates that $\mathrm{InN}$ mole fractions for both the areas are similar.

In a reasonable quality semiconductor, the measured lifetime at $32 \mathrm{~K}$ is principally dominated by the radiative lifetime, because most of the nonradiative processes are frozen. Then, the nearly identical and reasonably short $\tau_{\mathrm{CL} \text {,eff value }}$ excludes the possibility that BSFs limit $\tau_{\mathrm{CL} \text {,eff }}$ values in the areas (1)-(3), because the radiative lifetime of excitons trapped in the $I_{1}$-type BSFs [39] or in the type-II QWs [40] formed within BSFs is much longer than the classical free or bound excitons in the case of $\mathrm{GaN}$ [29]. From the non-negligible CL peak energy variation being as small as up to $60 \mathrm{meV}$, as shown in figure $9(a)$, the InN mole fraction variation is estimated to be as small as $\pm 1 \%$. This is the reason why a remarkable change cannot be clearly found in the $\tau_{\mathrm{CL} \text {,eff }}$ value.

Because the morphological striation and $m$-plane tilt mosaic along the $a$-axis are severer than along the $c$-axis, the zonary pattern along the $c$-axis in the CL image (figure $8(b)$ ) may not originate from the $m$-plane tilt mosaic along the $a$-axis. One of the possibilities for the higher and more homogeneous InN mole fraction in the zonary areas (1) is that the region may have $\langle 000 \overline{1}\rangle$-oriented $\mathrm{N}$-polar $(-c)$ vicinal $m$-plane surface [23] due to the slight tilt along the $c$-axis, as $\eta_{\text {inc }}^{\text {In }}$ for $\mathrm{N}$ polar growth is higher than the Ga-polar growth according to the different atomic configurations [14, 41, 42]. The areas corresponding to spots (2) and (3) may contain flatter $m$-plane regions where $\eta_{\text {inc }}^{\text {In }}$ is lower than that of other inclined vicinal planes $[13,24]$.

Finally, the reversed CL intensity image in the figureof-eight patterns shown in figures $8(e)$ and $(f)$ is attributed to different $\eta_{\text {inc }}^{\text {In }}$ values for different growth fronts. As shown in the AFM image in figures $8(a)$ and $(g)$, the figure-of-eight patterns seem to exist at the positions where two vicinal planes inclined to opposite directions (along the $a$-axis) appear. Then, one of the growth fronts has an inclined Ga-polarity $(+c)$ plane edge and the other has the N-polarity $(-c)$ one. In this case, because $\eta_{\text {inc }}^{\text {In }}$ for N-polar growth is higher than the Ga-polar growth, as described [14, 41, 42], all the figure-of-eight patterns within the domain structure should have the same directional shapes. This is indeed the case, as confirmed by figures $8(b)$ and $4(b)$.

\section{Conclusions}

Advantages and remaining issues of state-of-the-art $m$-plane FS-GaN substrates for $m$-plane $\operatorname{In}_{x} \mathrm{Ga}_{1-x} \mathrm{~N}$ epitaxial growth are described. According to the reduction in TD and BSF densities, improved $\eta_{\text {int }}^{\text {eq }}$ and short radiative lifetime are achieved. The FWHM values for the $\mathrm{x}$-ray $\omega$-rocking curves remain unchanged as the substrate values for $x=<0.14$. As the surface flatness is greatly improved, $\eta_{\text {inc }}^{\text {In }}$ is lower than the cases for conventional $c$-plane growth and $m$-plane 
growth on a defective GaN substrate. The former originates from nonidentical surface kinetics, and the latter is due to the reduction in the area of inclined and tilted planes. Submicrometer-wide zonary patterns parallel to the $c$-axis and $2 \mu \mathrm{m}$ long axis figure-of-eight patterns parallel to the $a$-axis are clearly visualized in the monochromatic CL intensity images. Because the STRCL measurement reveals very little spatial variation of low-temperature radiative lifetime, the slight peak energy variation is interpreted to originate from nonidentical $\eta_{\text {inc }}^{\text {In }}$ for the growing surfaces exhibiting various miscut angles. The figure-of-eight patterns are ascribed to originate from the anisotropic, severe $m$-plane tilt mosaic along the $a$-axis of the GaN substrate, and the zonary patterns may originate from the $m$-plane tilt mosaic along the $c$-axis. Further reduction in the tilt and twist mosaics is necessary for HVPE of FS-GaN substrates, in order to grow homogeneous InGaN epilayers. The use of dislocation-free and bowing-free real FS-GaN seeds enlarged from spontaneously nucleated crystals is a promising protocol for the bulk GaN growth by HVPE, as is the case with the ammonothermal growth of real bulk GaN crystals developed by Dwiliński et al [43, 44].

\section{Acknowledgments}

This work was supported in part by grant-in-aids of CANTech, IMRAM, Tohoku University, Scientific Research on Priority Areas (no 18069001) under MEXT, and NEDO programs by METI, Japan. The work in Switzlerland was supported by the National Centre of Competence in Research Quantum Photonics and Research Instrument of the Swiss National Science Foundation, Switzerland.

\section{References}

[1] Speck J S and Chichibu S F 2009 MRS Bull. 34304 (review article)

[2] Takeuchi T, Sota D, Katsuragawa M, Komori M, Takeuchi H, Amano H and Akasaki I 1997 Japan. J. Appl. Phys. 36 L382

[3] Chichibu S, Azuhata T, Sota T and Nakamura S 1996 Appl. Phys. Lett. 694188

[4] Takeuchi T, Amano H and Akasaki I 2000 Japan. J. Appl. Phys. 39413

[5] Romanov A E, Baker T J, Nakamura S and Speck J S 2006 J. Appl. Phys. 100023522

[6] Chichibu S F et al 2006 Nature Mater. 5810

[7] Chakraborty A, Haskell B A, Keller S, Speck J S, DenBaars S P, Nakamura S and Mishra U K 2004 Appl. Phys. Lett. 855143

[8] Chakraborty A, Haskell B A, Keller S, Speck J S, DenBaars S P, Nakamura S and Mishra U K 2005 Japan. J. Appl. Phys. 44 L173

[9] Haskell B A, Wu F, Craven M D, Matsuda S, Fini P T, Fujii T, Fujito K, DenBaars S P, Speck J S and Nakamura S 2003 Appl. Phys. Lett. 83644

[10] Haskell B A, Baker T J, McLaurin M B, Wu F, Fini P T, DenBaars S P, Speck J S and Nakamura S 2005 Appl. Phys. Lett. 86111917

[11] Chakraborty A, Keller S, Meier C, Haskell B A, Keller S, Waltereit P, DenBaars S P, Nakamura S, Speck J S and Mishra U K 2005 Appl. Phys. Lett. 86031901

[12] Onuma T, Chakraborty A, Haskell B A, Keller S, DenBaars S P, Speck J S, Nakamura S, Mishra U K, Sota T and Chichibu S F 2005 Appl. Phys. Lett. 86151918
[13] Koyama T et al 2006 Appl. Phys. Lett. 89091906

[14] Onuma T et al 2007 J. Vac. Sci. Technol. B 251524

[15] Bertram F, Srinivasan S, Geng L, Ponce F A, Riemann T and Christen J 2002 Appl. Phys. Lett. 803524

[16] Schmidt M C, Kim K-C, Sato H, Fellows N, Masui H, Nakamura S, DenBaars S P and Speck J S 2007 Japan. J. Appl. Phys. 46 L126

[17] Okamoto K, Ohta H, Chichibu S F, Ichihara J and Takasu J 2007 Japan. J. Appl. Phys. 46 L187

[18] Schmidt M C, Kim K-C, Farrell R M, Feezell D F, Cohen D A, Saito M, Fujito K, Speck J S, DenBaars S P and Nakamura S 2007 Japan. J. Appl. Phys. 46 L190

[19] Enya Y et al 2009 Appl. Phys. Express 2082101

[20] Tyagi A et al 2010 Appl. Phys. Express 3011002

[21] Fujito K, Kiyomi K, Mochizuki T, Oota H, Namita H, Nagao S and Fujimura I 2008 Phys. Status Solidi a 2051056

[22] Chichibu S F, Yamaguchi H, Zhao L, Kubota M, Okamoto K and Ohta H 2008 Appl. Phys. Lett. 92091912

Chichibu S F, Yamaguchi H, Zhao L, Kubota M, Okamoto K and Ohta H 2008 Appl. Phys. Lett. 93129901 (erratum)

[23] Hirai A, Jia Z, Schmidt M C, Farrell R M, DenBaars S P, Nakamura S, Speck J S and Fujito K 2007 Appl. Phys. Lett. 91191906

[24] Chichibu S F, Yamaguchi H, Zhao L, Kubota M, Onuma T, Okamoto K and Ohta H 2008 Appl. Phys. Lett. 93151908

[25] Chichibu S, Azuhata T, Sota T and Nakamura S 1997 Appl. Phys. Lett. 702822

[26] Kagaya M, Corfdir P, Ganière J D, Deveaud-Plédran B, Grandjean N and Chichibu S F 2011 Japan. J. Appl. Phys. 50111002

[27] Fujito K, Kubo S, Nagaoka H, Mochizuki T, Namita H and Nagao S 2009 J. Cryst. Growth 3113011

[28] Merano M et al 2005 Nature 438479

[29] Corfdir P, Ristić J, Lefebvre P, Zhu T, Martin D, Dussaigne A, Ganière J D, Grandjean N and Deveaud-Plédran B 2009 Appl. Phys. Lett. 94201115

[30] Wu X H, Elsass C R, Abare A, Mack M, Keller S, Petroff P M, DenBaars S P, Speck J S and Rosner S J 1998 Appl. Phys. Lett. 72692

[31] Nishizuka K, Funato M, Kawakami Y, Fujita Sg, Narukawa Y and Mukai T 2005 Appl. Phys. Lett. 853122

[32] Yamada H, Iso K, Saito M, Fujito K, DenBaars S P, Speck J S and Nakamura S 2007 Japan. J. Appl. Phys. 461117

[33] Onuma T, Okamoto K, Ohta H and Chichibu S F 2008 Appl. Phys. Lett. 98091112

[34] Harris C I, Monemar B, Amano H and Akasaki I 1995 Appl. Phys. Lett. 67840

[35] Im J S, Kollmer H, Off J, Sohmer A, Scholz F and Hangleiter A 1998 Phys. Rev. B 57 R9435

[36] Chichibu S et al 1999 Mater. Sci. Eng. B 59298

[37] Chichibu S F, Uedono A, Onuma T, Sota T, Haskell B A, DenBaars S P, Speck J S and Nakamura S 2005 Appl. Phys. Lett. 86021914

[38] Chichibu S, Azuhata T, Sota T and Nakamura S 1996 J. Appl. Phys. 792784

[39] Stampfl C and Van de Walle C G 1998 Phys. Rev. B 57 R15052

[40] Salviati G et al 1999 Phys. Status Solidi a 171325

[41] Zywietz T K, Neugebauer J and Scheffler M 1999 Appl. Phys. Lett. 741695

[42] Sumiya M, Yoshimura K, Ohtsuka K and Fuke S 2000 Appl. Phys. Lett. 762098

[43] Dwiliński R, Doradziński R, Garczyński J, Sierzputowski L P, Puchalski A, Kanbara Y, Yagi K, Minakuchi H and Hayashi H 2008 J. Cryst. Growth 3103911

[44] Dwiliński R, Doradziński R, Garczyński J, Sierzputowski L P, Puchalski A, Kanbara Y, Yagi K, Minakuchi H and Hayashi H 2009 J. Cryst. Growth 3113015 